\title{
Understanding the Contribution of HRM Bundles for Employee Outcomes Across the Life-Span
}

\author{
Klaske N. Veth ${ }^{1,2 *}$, Hubert P. L. M. Korzilius', Beatrice I. J. M. Van der Heijden ${ }^{2,3,4,5,6}$, \\ Ben J. M. Emans ${ }^{7}$ and Annet H. De Lange ${ }^{3,8}$ \\ ${ }^{1}$ Institute of Business Management, HRM, Hanze University of Applied Sciences, Groningen, Netherlands, ${ }^{2}$ Institute for \\ Management Research, Radboud University, Nijmegen, Netherlands, ${ }^{3}$ Faculty of Management, Science \& Technology, Open \\ University of the Netherlands, Heerlen, Netherlands, ${ }^{4}$ Faculty of Economics \& Business Administration, Ghent University, \\ Ghent, Belgium, ${ }^{5}$ School of Management, Hubei University, Wuhan, China, ${ }^{6}$ School of Management, Kingston University, \\ Kingston upon Thames, United Kingdom, ${ }^{7}$ Faculty of Economics \& Business, University of Groningen, Groningen, \\ Netherlands, ${ }^{8}$ Institute of HRM, HAN University of Applied Sciences, Nijmegen, Netherlands
}

\section{OPEN ACCESS}

Edited by:

Llewellyn Ellardus Van Zyl, Eindhoven University of Technology,

Netherlands

Reviewed by:

Joan Torrent-Sellens,

Open University of Catalonia, Spain

Giulio Arcangeli,

University of Florence, Italy

*Correspondence: Klaske N. Veth

k.n.veth@pl.hanze.nl

Specialty section: This article was submitted to

Organizational Psychology, a section of the journal Frontiers in Psychology

Received: 29 May 2019 Accepted: 24 October 2019 Published: 15 November 2019

Citation:

Veth KN, Korzilius HPLM, Van der Heijden BIJM, Emans BJM

and De Lange AH (2019)

Understanding the Contribution of HRM Bundles for Employee

Outcomes Across the Life-Span.

Front. Psychol. 10:2518.

doi: 10.3389/fpsyg.2019.02518
Using the Job Demands-Resources model literature and the life-span theory as scholarly frameworks, we examined the effects of job demands and job resources as mediators in the relationship between bundles of used HRM practices and employee outcomes. In addition, we tested for age differences in our research model. Findings confirmed the hypothesized original 2-factor structure representing maintenance and development HRM practices. Structural Equation Modeling analyses showed that the maintenance HRM bundle related directly and negatively to employee outcomes, without moderating effects of age. However, job resources appeared to mediate this relationship in a positive way as it also did for the development HRM bundle. Whereas this study showed the 'driving power' of the actual use of HRM bundles through job resources, regardless of the employee's age, this study also suggests a 'dark side' of HRM. In particular, we found that development HRM bundles may also increase job demands, which, in turn, may result in lower levels of beneficial employee outcomes. These empirical outcomes demonstrate the strength of the driving power eliciting from job resources preceded by any HRM bundle. Moreover, this effect appears to apply to employees of all ages. Our moderated-mediation model appeared robust for several control variables. Overall, this study provides an extension of the well-known Job Demands-Resources model by including maintenance and development bundles of HRM practices used by employees that have a differential effect on job demands and job resources which in turn have an impact on employee outcomes.

Keywords: Human Resource Management (HRM), HRM bundles, employee outcomes, job demands, job resources

\section{INTRODUCTION}

Previously, ample Human Resource Management (HRM) research has paid attention to the effects of HRM on individual employee attitudes and behavior (e.g., Kuvaas, 2008; Van de Voorde et al., 2012; Pak et al., 2018). After all, it is through employees' attitudes and behavior that organizational competitive advantage can be gained (Paauwe et al., 2013; De Vos et al., 2018). To better understand how HRM contributes to shape employees' attitudes and behavior, additional 
research is needed to examine possible mediating linkages between HRM implementation and employee outcomes (see also Bowen and Ostroff, 2004). For that reason, and in line with previous suggestions by scholars in the field (Van de Voorde and Boxall, 2014; Albrecht et al., 2015), the Job DemandsResources model (Demerouti et al., 2001b; Bakker et al., 2003) is used to investigate the influence of HRM on employee outcomes, through the hypothesized mediating role of workrelated characteristics. Hence, this study extends the relationships between demands/resources and employee outcomes by adding the more distant-like HRM as a foundation of the more closely related demands and resources.

The aforementioned relationships occur in the context of an aging labor force. According to life-span theory, aging is generally associated with both gains and losses (Baltes and Baltes, 1990; Kanfer and Ackerman, 2004), which are assumed to affect the relationship between HRM, work-related characteristics, and employee outcomes. Specifically, nowadays, organizations are facing the combination of a constant and rather low number of young employees, due to continuous low birth rates, and the significant extension of life expectancy at birth within European and other developed countries (Eurostat, 2013; Hertel et al., 2013). This might require adaptations in HRM strategies, such as career development and retirement policies (Hedge et al., 2006) in order to find ways to enable workers into a prolonged working life (De Lange et al., 2015). Life-span theories (Kanfer and Ackerman, 2004; Baltes et al., 2006; Barnes-Farrell and Matthews, 2007; Maurer, 2007) have shed light on changes in workers' needs, which have implications for the specific need for HRM throughout their career. However, evidence on how relationships between aging and employee outcomes take shape is not unambiguous. This illustrates the complexity of the broad concept that aging comprises (Zacher et al., 2018). This draws attention to the question of how managers may further develop and maintain an aging and active workforce (Hedge et al., 2006; Shultz and Wang, 2011; Hertel et al., 2013).

To date, to the best of our knowledge, no study has addressed the impact of mediators upon the relationship between HRM and employee outcomes, together with the effect of age (Korff et al., 2009). This is an important omission, since evidence suggests that employees' work characteristics, such as job resources, have an impact on their attitudes and behavior (e.g., Bakker et al., 2003) across the life-span. Considering these limitations, the contribution of our paper is fourfold. Firstly, we aim to extend the Job Demands-Resources model literature (Demerouti et al., 2001b; Bakker et al., 2003) by investigating the relationships between several bundles of HRM practices that are actually used by employees, work-related aspects, and employee outcomes. To investigate these relationships, the JD-R model is used to discern mediating mechanisms, such as job demands (i.e., mental and emotional load) and job resources (i.e., learning opportunities and support from the supervisor), that are provoked by HRM practices, and that ultimately give rise to employee outcomes. Secondly, findings from life-span developmental psychology have identified various systematic age-related changes in human functioning (Baltes et al., 2006; Barnes-Farrell and Matthews, 2007; Maurer, 2007), work-related attitudes, and motivation
(Finegold et al., 2002; Kanfer and Ackerman, 2004). Therefore, age has been included as a moderating factor in our research model. Thirdly, ample research has examined relationships between employees' perceptions of HRM practices and employee outcomes (Gould-Williams, 2007; Macky and Boxall, 2007; Kuvaas, 2008; Gellatly et al., 2009; Gong et al., 2009; Paauwe, 2009). However, these perceptions can inevitably vary from its actual use (Gratton and Truss, 2003; Conway and Monks, 2008; Nishii et al., 2008; Snape and Redman, 2010). To date, there are hardly any empirical studies investigating the actual use of HRM (for an exception see Bal and De Lange, 2014). In our view, this is an omission since the actual use of HRM might also have an effect on employee outcomes. Fourthly, by examining HRM bundles, we go beyond several HRM studies that have taken into account isolated HRM practices (see also Huselid, 1995; Kooij et al., 2014; Veth et al., 2015). Following MacDuffie (1995), HRM bundles are specified as sets of interrelated and internally consistent HRM practices that are aimed to contribute to more productivity and quality than each HRM practice in itself. By combining these four contributions, our empirical work comprises a unique compound of perspectives.

Before elaborating on our theoretical framework, we explain our research setting. This study has been conducted in the Netherlands incorporating three working organizations from three different sectors: transport, healthcare, and research and education. Similar to many developed and developing countries, the Netherlands is confronted with unprecedented and rapid aging of populations and workforces alike (Ilmarinen, 2009; Chand and Tung, 2014). Furthermore, in order to warrant generalizability and to test the robustness of findings across occupational sectors, we explicitly included three distinctive sectors and strived for an equal distribution of both males and females, across age groups, from profit and not-forprofit organizations. Our research model, incorporating all hypothesized relationships, is presented in Figure 1.

\section{EXTENDING THE JOB DEMANDS-RESOURCES MODEL FRAMEWORK BY INCORPORATING HRM}

The research model for this study comprises an extension of the Job Demands-Resources model (JD-R) (Demerouti et al., 2001b; Bakker et al., 2003). According to the JD-R model, regardless of the specific occupation that is dealt with, two broad categories of work characteristics, can be distinguished: job demands (in this study mental load, emotional load, pace and amount of work) and job resources (in this study independence, learning opportunities, variety of work, support from supervisor, and support from colleagues). Job demands are those physical, social, or organizational aspects of the job that require sustained physical and/or psychological effort, and are, therefore, associated with physiological and/or psychological costs (Bakker et al., 2003, p. 344). Job resources refer to those physical, psychological, social, or organizational aspects of the job that: (1) may reduce 


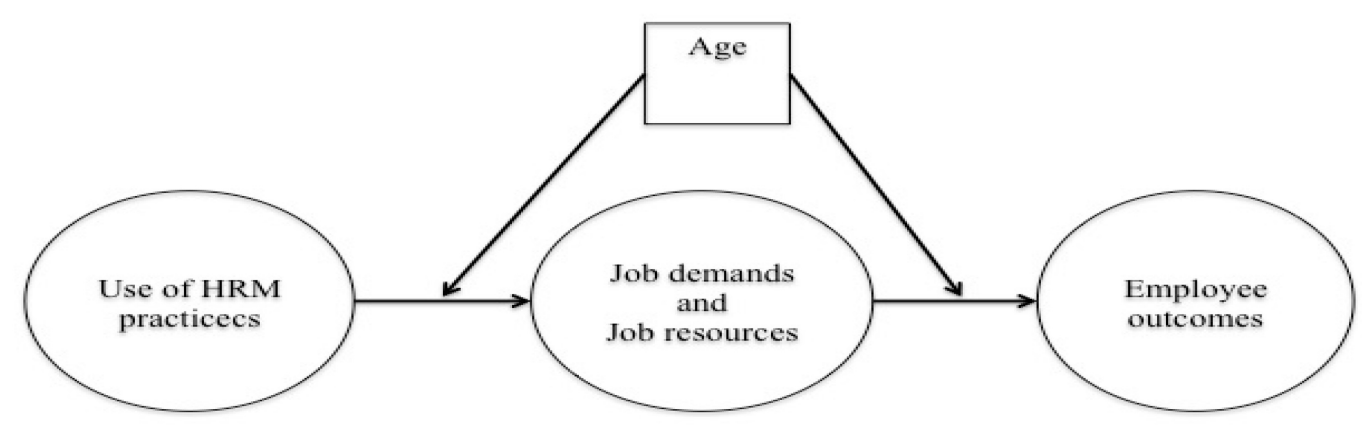

FIGURE 1 | Research model.

job demands and the associated physiological and psychological costs; (2) are functional in achieving work goals, and: (3) stimulate personal growth, learning, and development (Bakker et al., 2003, p. 344). According to the JD-R model, job resources have motivating potential (Bakker and Demerouti, 2007, 2014), and the impact of work environments, characterized by many job resources, on employee outcomes has been widely acknowledged (Schaufeli and Bakker, 2004; Salanova et al., 2005; Llorens et al., 2007; Mauno et al., 2007; Hakanen et al., 2008). Our choice of outcomes variables is argued below.

The World Health Organization (2016) considers the following three elements as crucial for healthy work in which workers and managers collaborate to use a continual process to improve people's well-being at work; (1) work engagement, (2) employability, and (3) health. First, as work engagement is also a central variable in the motivation process of the JD-R model that is expected to affect employee performance (Bakker and Demerouti, 2008), this variable is included as one of the employee outcomes in the present study. Work engagement is defined as a positive, fulfilling work-related state of mind that is characterized by vigor, dedication, and absorption (Schaufeli et al., 2002). Second, employability is also referred to as a positive outcome (Thijssen et al., 2008), and has been defined as 'the capacity of continuously fulfilling, acquiring or creating work through the optimal use of competences' (Van Der Heijde and Van Der Heijden, 2006, p. 453). Employability (or career potential) enables employees to cope with fast changing job requirements (Van Der Heijde and Van Der Heijden, 2006; Van der Heijden et al., 2009). Third, considerable previous research has shown the association between work characteristics and employee health (i.e., Wilson et al., 2004). As work is an influential part of employees' lives, it also affects the quality of an individual's life and his or her perceived mental health (Harter et al., 2002). Therefore, health is included as a third employee outcome. As argued by Van der Klink et al. (2016), and recently reconfirmed by Pak et al. (2018), these three employee outcomes are considered as aids to optimal functioning, and fit the recent trend to concentrate on optimal functioning.

Much previous empirical evidence suggests that work characteristics (job demands and resources) enhance employee outcomes, such as work engagement (Demerouti et al., 2001a,b; Salanova et al., 2005; Mauno et al., 2007). In this study, the JD-R model is extended with an examination of the impact of HRM on work characteristics, and, subsequently, on employee outcomes. In this regard, HRM is considered as a more distant-like provision of practices by the organization, whereas work characteristics are more closely related to the employee's work(place), and therefore easier to influence. Earlier empirical evidence already suggests that work characteristics have an impact on employee's attitudes and behaviors (e.g., Bakker et al., 2003), and therefore, we argue that they can mediate the relationship between HRM and employee outcomes. Hence, the underlying idea is that HRM is assumed to influence job demands and resources, which, may, subsequently, have an impact on employee outcomes. How these relationships manifest themselves exactly, depends on the character of the bundle of HRM practices.

The current empirical study examines the impact of two categories of bundles of HRM practices. We used an existing list of HRM practices (Kooij et al., 2010) that comprises all kinds of practices (ranging from management practices, such as job development interviews, to fringe practices, such as a sabbatical). Based on the results of a pilot study amongst HRM professionals, we added seven (age-related) HRM practices to the operationalization by Kooij et al. (2010), such as child care. In line with existing literature (e.g., Armstrong-Stassen and Schlosser, 2010; Kooij et al., 2014), we have first bundled HRM practices into sets of interrelated and internally consistent HRM practices aimed at achieving the same organizational purpose (MacDuffie, 1995). First, this distinction has been made conceptually in the theoretical framework, and thereafter confirmed using statistical analyses. The first category includes so-called maintenance HRM practices, referring to those practices that are aimed at retaining workers at their current level of functioning, or at recovery after a loss (Kooij et al., 2010). It is classified as the maintenance HRM bundle because of the shared goals of the specific HRM practices it entails, all being focused on preserving the status quo. Examples are part-time work and attention for health. The second category is called the development HRM bundle and consists of practices striving to reach higher levels of employee functioning. Regardless of the content of the specific HRM practices, all practices in this bundle are focused on growth, learning new tasks, and extending the employee's horizon. Examples are continuous development and task enrichment. 
However, in this study the focus lies on the actual use of HRM practices by employees, rather than on employees' perceptions on intended or available HRM practices. We argue that it is insufficient to only shed light on employees' perceptions about HRM (Gratton and Truss, 2003; Conway and Monks, 2008; Snape and Redman, 2010), because these can vary from its intentions and actual use (Nishii et al., 2008). Though it might be interesting to take into account the intentions behind the HRM practices at a strategic level, as reported by HRM professionals (e.g., Khilji and Wang, 2006; Nishii et al., 2008), or, employees' perceptions of those HRM practices, in the end it all evolves around the actual use of those HRM practices by the employees (Legge, 1995; Keenoy, 1999; Purcell, 1999; Truss, 2001; Khilji, 2002; Lee and Allen, 2002) as the latter is accountable for real changes in employee outcomes.

Building upon the JD-R model (Demerouti et al., 2001b), we expected these two categories of HRM bundles to have differential effects on the work characteristics (job demands and resources) and, through these, on employee outcomes. Earlier scholarly work applying the JD-R model has already shown that job resources, such as independence in one's work, social support from one's supervisor and near colleagues, task variety, and opportunities to learn, are positively associated with employee outcomes. In a similar vein, job demands are defined as aspects of work that require effort. Hence, job demands are associated with costs and in line with the JD-R model assumed to negatively affect employee outcomes (Schaufeli and Bakker, 2004; Demerouti and Bakker, 2011). The rationale of how these mechanisms are related to the distinguished categories of HRM bundles is established below.

First, the maintenance HRM bundle is intended to result in diminishing job demands which will, subsequently, positively impact employee outcomes. For instance, working part-time allows employees to continue their career as well as to pursue their lives beyond the workplace (Collins, 2003), which will reduce mental load and, in the end, increase employee outcomes. Such an effect is reinforced by other practices such as flexible work conditions and telecommuting, altogether being ingredients of the maintenance HRM bundle.

Second, the relationship between the actual use of maintenance HRM practices and employee outcomes, through job resources, is assumed to have a negative character. For instance, 'part-time work' also implies a decreased amount of opportunities to learn (job resources), given the reduced presence at the workplace for the specific employee, and, in turn, impacts employee outcomes negatively.

Third, the so-called development HRM bundle contains a group of interconnected HRM practices that have the capacity to make work more resourceful (Van De Voorde et al., 2016). For instance, the development HRM bundle is focused on growth and expanding horizons, and may therefore be expected to increase job resources, such as support from one's supervisor. Hence, we expect that practices being part of the developmental HRM bundle result in increased job resources, which, in turn, will positively impact employee outcomes.

Fourth, this development HRM bundle may also make the employee's work more challenging and intense
(Van De Voorde et al., 2016). For example, the use of training implies a time-consuming effort and, therefore, may lead to increased job demands, such as mental load, and is subsequently assumed to result in decreased employee outcomes. Hence, we believe that, unfortunately, HRM can also have 'a dark side', which is in line with some earlier scholarly research (Jensen et al., 2013). Specifically, research related to enhancing employee skills, that is, increasing their motivation and facilitating empowerment (Wright and Boswell, 2002), showed results of employees feeling being exploited. For instance, attending training programs can be at the expense of employee's time and energy and can therefore also lead to increased working pressure. These relationships, on the one hand, from maintenance HRM, through a decreased perception of job resources, to diminished employee outcomes, and, on the other hand, from development HRM, through an increased perception of job demands, to decreased employee outcomes, are the side effects of HRM. However, in general, HRM is acknowledged to be an important function that adds value to employee attitudes and behavior (Snape and Redman, 2010), by reducing job demands (enforced by maintenance HRM) and by improving job resources (enforced by development HRM). Following this line of reasoning, we hypothesized the following:

Hypothesis 1a: The positive relationship between the use of the maintenance HRM bundle and employee outcomes is (partially) mediated by job demands.

Hypothesis 1b: The positive relationship between the use of the maintenance HRM bundle and employee outcomes is (partially) mediated by job resources.

Hypothesis 1c: The positive relationship between the use of the development HRM bundle and employee outcomes is (partially) mediated by job demands.

Hypothesis 1d: The positive relationship between the use of the development HRM bundle and employee outcomes is (partially) mediated by job resources.

\section{EXTENDING THE JD-R MODEL FRAMEWORK BY INCORPORATING LIFE-SPAN THEORY}

Since employees have to work longer, due to an increased retirement age (Hedge and Borman, 2012), it is of utmost importance to examine the role of age in the relationship between HRM bundles and employee outcomes. Though there is voluminous literature that addresses the relevance of single or bundled HRM practices (e.g., Huselid, 1995; Becker and Gerhart, 1996; Delery and Doty, 1996; Guest, 1997, 2002; Paul and Anantharaman, 2003; Wright et al., 2005; Schuler and Jackson, 2007), up to now, only a few researchers have conducted empirical research on how age affects the relationship between HRM and important outcomes (e.g., Hedge et al., 2006; Staudinger et al., 2008). Building upon life-span theories, previously, scholars have identified some basic changes as people age (e.g., Baltes et al., 2006; Barnes-Farrell and Matthews, 2007; Maurer, 2007; Bal and De Lange, 2014). Therefore, changes in 
work-related attitudes and work motivation tied to life-span are to be expected (e.g., Kanfer and Ackerman, 2004).

According to life-span theorizing (Baltes et al., 2006), human development goes along differential trajectories that entail gains on some dimensions of human behavior and stability and/or losses on other dimensions. The so-called SOC model (see also Baltes and Baltes, 1990; Baltes and Carstensen, 1996) posits that successfully aging people Select subjectively their goals, Optimize their strategies for goals attainment, and Compensate for age-related losses. This process of adaptation is a dynamic, life-long development in which people and their environment mutually influence each other (Baltes, 1987). This age-dynamic proposition is supported by Ebner et al. (2006), who found, that as people age and have increasingly to deal with losses, for instance as regards their fluid intelligence, their goal focus shifts gradually from a predominant growth orientation to a goal focus on maintenance and prevention. Indeed, in their meta-analysis of 86 studies, Kooij et al. (2011) revealed that work-related motives change with age, specifically, from a stronger focus on extrinsic growth-related motives among younger workers to more intrinsic work-related motives for older workers. Therefore, in line with life-span theorizing, we argue that the impact of specific HRM practices or bundles may be dependent on the age of the involved employees (Ng and Feldman, 2008). Since the above-mentioned losses (for example in occupational competences) specifically occur in older age, SOC theory argues that the allocation of maintenance HRM or job demands used for maintenance and regulation of loss (i.e., compensation) will increase with age, whereas the provision of development HRM or job resources aimed at growth (i.e., optimization) will decrease with age (Baltes et al., 1999). These changing employee needs affect the actual use of HRM bundles, and therefore a moderating role of age is expected. More specifically, we hypothesized the following:

Hypothesis 2: The (partially) mediated relationship between the use of both the maintenance and the development HRM bundles respectively, on the one hand, and employee outcomes, on the other hand, through job demands and job resources, is moderated by age, such that the higher the age, the stronger the relationship in case the maintenance HRM bundle is the predictor (2a), and the weaker the relationship in case the development HRM bundle is the predictor (2b).

\section{MATERIALS AND METHODS}

\section{Respondents and Procedure}

The data collection was done by means of an on-line questionnaire among 6,000 employees working in three Dutch working organizations from three different occupational sectors: transport, healthcare, and research and education. The questionnaires were distributed using the web-based tool Qualtrics Labs Inc. (2012), and were sent to all employees including the ones working as managers. The respondents were assured confidentiality, were informed about the added value of the research, and were offered some rewards in recognition of their participation. Initially, a total of 2,240 workers responded to the survey, representing a response rate of approximately $20 \%$. Data from respondents who did not complete the whole questionnaire were list-wise excluded from further analyses. This resulted in a total sample of 1,121 respondents measuring age as a continuous metric variable in order to have more statistical power (i.e., establishing existing effects by means of the statistical tests) and to be able to comprehensibly study age as moderator in the various SEM analyses. A missing value analysis showed no significant differences between the data set of included and excluded respondents for gender, part-time versus full-time workers, age $\left[\chi^{2}(1)=0.13, p=0.72 ; \chi^{2}(1)=0.50, p=0.48\right.$; $\left.\chi^{2}(1170)=0.31, p=0.76\right]$. However, the category of respondents contained relatively more higher educated employees compared to the group of excluded ones $\left[\chi^{2}(6)=27.56, p<0.001\right]$. The mean age of the respondents was 46.9 years $(S D=10.2)$ and their mean job tenure was $8.54(S D=8.88)$. Please, see Table 1 for an overview of sample characteristics.

\section{Measures}

\section{Employee Outcomes}

The Utrecht Work Engagement Scale (UWES) developed by Schaufeli et al. (2002) was used to measure work engagement. This 9-item questionnaire measuring three components, vigor (3 items: e.g., 'When I get up in the morning, I feel like going to work'), dedication (3 items: e.g., 'I am enthusiastic about my job'), and absorption (3 items: e.g., 'When I am working, I forget everything else around me'), was rated

TABLE 1 | Characteristics of the sample.

\begin{tabular}{|c|c|}
\hline Variable & $n(\%)$ \\
\hline Gender & 1152 \\
\hline Male & $311(27.0)$ \\
\hline Female & $841(73.0)$ \\
\hline Marital status & 1167 \\
\hline Unmarried & $118(10.1)$ \\
\hline Married/cohabiting/partnership & $961(82.3)$ \\
\hline Divorced & $79(6.8)$ \\
\hline Widowed & $9(0.8)$ \\
\hline Children & 1162 \\
\hline Yes & $903(77.7)$ \\
\hline No & 259 (22.3) \\
\hline Highest completed education & 1171 \\
\hline Elementary school & $5(0.4)$ \\
\hline Lower vocational education & $47(4.0)$ \\
\hline Secondary school & $149(12.7)$ \\
\hline Secondary vocational education & $370(31.6)$ \\
\hline Higher vocational education & $259(22.1)$ \\
\hline Academic education & $291(24.9)$ \\
\hline Other & $50(4.3)$ \\
\hline Contract & 1158 \\
\hline Part-time & $842(72.7)$ \\
\hline Full-time & $316(27.3)$ \\
\hline Management & 1152 \\
\hline Line/staff/project & $243(21.1)$ \\
\hline Non-management & 909 (78.9) \\
\hline
\end{tabular}


on a seven-point Likert-scale ranging from 1 ('never') to 7 ('always'). The UWES subscales have shown acceptable levels of internal consistency with McDonald's omega ${ }^{1}$ of 0.79 , 0.81 , and 0.81 , respectively. We computed an overall work engagement score, as was recommended by Schaufeli et al. (2006; McDonald's omega $=0.94$ ).

The Employability instrument developed by Van Der Heijde and Van Der Heijden (2006; see also Van der Heijden et al., 2009) was used to measure employability. The 47 -item list measuring five components, occupational expertise (15 items: e.g., 'I consider myself competent to engage in in-depth, specialist discussions in my job domain'), anticipation and optimization (8 items: e.g., 'How much time do you spend improving the knowledge and skills that will be of benefit to your work?'), personal flexibility (8 items: e.g., 'How easily would you say you can adapt to changes in your workplace?'), corporate sense (7 items: e.g., 'I am involved in achieving my organization's/department's mission'), and balance (9 items: e.g., 'I suffer from work-related stress'), was rated on a six-point Likert-scale ranging from 1 ('not at all'/'very badly'/'very little'/'never') to 6 ('extremely'/'a considerable degree'/'very well'/'a very great deal'/'very often'). The employability instrument has shown acceptable levels of internal consistency with McDonald's omegas of $0.91,0.83,0.77$, 0.86 , and 0.83 , respectively. McDonald's omega of the overall employability scale was 0.93 .

The SF-36 Health-scale developed by Ware and Sherbourne (1992) was used to measure general health perception. The 5-item questionnaire (e.g., 'I am as healthy as anybody I know') was rated on a five-point Likert-scale ranging from 1 ('definitely false') to 5 'definitely true'). The SF-36 Health-scale has shown an acceptable level of internal consistency with a McDonald's omega of 0.74 .

\section{Job Demands}

The Mental load and Emotional load, and the Pace and amount of work scales developed by Van Veldhoven et al. (2002) were used to measure job demands. The first two 7-item instruments (mental load e.g., 'Does your work demand a lot of concentration?' and emotional load e.g., 'Does your work demand a lot from you emotionally?') were rated on a four-point Likert-scale ranging from 1 ('never') to 4 ('always'). The latter 11item instrument pace and amount of work (e.g., 'Do you have to work fast?') was rated on a four-point Likert-scale ranging from 1 ('never') to 4 ('always'). All three scales have shown acceptable levels of internal consistency with McDonald's omegas of 0.87, 0.77 , and 0.83 , respectively.

\section{Job Resources}

The scales Independence in your work, Opportunities to learn, and Variety in your work developed by Van Veldhoven et al. (2002) were used to measure job resources. The 11-item instrument of Independence in your work (e.g., 'Do you have

\footnotetext{
${ }^{1}$ For scale reliabilities, we reported the McDonald's omega rather than Cronbach's alpha because it is a more robust method as it takes into account the possible differential impact of the various items of a scale (McNeish et al., 2018). Omega was calculated with the statistical package JASP (V. 0.10.2), University of Amsterdam.
}

freedom in carrying out your work activities?'), the 4-item instrument of Opportunities to learn (e.g., 'Do you learn new things in your work?'), and the 6-item instrument of Variety in your work (e.g., 'Is your work varied?') were rated on a four-point Likert-scale ranging from 1 ('never') to 4 ('always'), and from 1 ('not at all') to ('very much'). All three scales have shown acceptable levels of internal consistency with McDonald's omega's of $0.91,0.83$, and 0.75 , respectively. In addition, the scales of Social support from the supervisor and Social support from colleagues developed by Van der Heijden $(2002,2003)$ were used to measure job resources. Both 4-item instruments (e.g., 'Is your immediate supervisor able to appreciate the value of your work and its results?' and 'Do your immediate colleagues give you supportive advice?') were rated on a six-point Likert scale ranging from 1 ('never'/'absolutely not') to 6 ('very often'/'to strong degree'). Both scales have shown good levels of internal consistency with McDonald's omega's of 0.83 and 0.80 .

\section{HRM Bundles}

To identify commonly examined HRM practices that are in use by employees in the involved organizations, we first identified 21 relevant age-related HRM practices, in line with Kooij et al. (2010). In addition, seven age-related HRM practices were included: flexible work, telecommuting, attention for health, sport facilities, child care, paid parental leave, and paid care leave. Based on a pilot-study amongst six HRM professionals who agreed that all items were unambiguous and understandable as regards their wording with the Dutch version of Kooij et al. (2010) for our target group of respondents, the final list of HRM practices was established (see Appendix). For measuring the respondent's use of HRM practices, preliminary questions were asked first about the availability of those practices. Subsequently, for practices that were said to be available, the respondents were asked whether they actually made use of them.

\section{Control Variables}

We used job duration (in years), gender (male/female), sector (transport, healthcare, and research and education), and management position (yes or no) as control variables in our analyses.

\section{Statistical Analysis}

The statistical analyses were performed with IBM SPSS Statistics (Version 25; Field, 2018) and IBM SPSS AMOS (Version 25; Arbuckle, 2006). First, we performed a confirmatory factor analysis (CFA) using maximum likelihood estimation on the latent variables (Byrne, 2010). Considering the large number of items (143) and thus the number of parameters that need to be estimated in relation to the number of respondents (Myers et al., 2011), we started with CFAs for the separate constructs. Based on Kooij et al. (2010), we assumed a 2-factorial structure of the 28 HRM practices. The other latent variables were considered to be 1 -factorial.

Second, we developed a factor measurement model with all concepts combined that formed the basis of the structural equation model (SEM) used for testing the hypotheses. In that process, we tested several models to decide which was the best 
final models taking into account the covariance between the latent factors (Wang and Wang, 2012). We started we a basic factor model and iteratively increased its complexity. As with increasing model complexity the fit deteriorated, we stopped after five models. These outcomes are likely to happen as the ratio of sample size to the number of variables in all these models will gradually lower, and will result in suboptimal fit indices. Still, we then checked whether the HRM bundles' data would be better estimated as a bi-factor model, where the HRM bundle is considered a general factor and the other factors are separately specified (Black et al., 2015), or whether these concepts should be seen as a factor model with formative rather than reflective indicators (Diamantopoulos et al., 2008).

In the CFA's we used modification indices to determine which error terms could be related. Items with non-significant factor loadings were deleted. We assessed the absolute, approximate, and incremental fit indices (Marsh et al., 2004; Kline, 2005; Schreiber et al., 2006; Byrne, 2010). In particular, we used the absolute fit indices Normed Chi-square statistic $\left(\chi^{2} / d f\right)$ and the Standardized root mean residual (SRMR), the approximate fit index Root mean square error of approximation (RMSEA), and the comparative fit indices Comparative fit index (CFI) and Tucker-Lewis Index (TLI). The following cut-off values of these fit indices were used to assess the model fit: $\chi^{2} / d f<2$ or 3, SRMR and RMSEA $<0.08$, CFI and TLI $>0.90$ or 0.95 . In addition, the Akaike information criterion (AIC) was used to evaluate different models in which smaller values indicate a better fit. In addition, we assessed convergent and discriminant validity based on the following criteria (Fornell and Larcker, 1981; Hair et al., 2010): Construct reliabilities $\geq 0.70$, Average Variance Extracted $(\mathrm{AVE})>0.50$, square root of AVE has to be greater than any of the construct inter-correlations. We also examined measurement quality by checking factor loadings and cross-loadings (Hair et al., 2010; McNeish et al., 2018).

Third, we calculated factor scores (see below) and carried out descriptive analyses and Pearson correlational analyses and partial correlations controlling for age.

Fourth, to test the hypothesized mediation effects for job demands and job resources in the relationship between maintenance and development HRM bundles, on the one hand, and employee outcomes, on the other hand (H1a-d); and the moderation effect of age in these relationships (H2a-b), we computed a moderated meditation SEM model. Given the issues with the sample size to variables ratio, we reduced the complexity of the hypothesized SEM model (i.e., number of free estimated parameters) by using manifest variables (see Jöreskog and Sörbom, 1993). To study the moderation effects of age, after centering, interaction terms of latent variables with age were computed. Following Schneider et al. (2005) and James et al. (2006), we started with a complete mediation model connecting all mediating variables to independent and dependent variables, and iteratively deleted non-significant paths. The indirect effects of HRM bundles via job demands and job resources on employee outcomes were assessed with a bias-corrected bootstrapping method of 1000 bootstrap samples that generated 95\% confidence intervals (CI) and standard errors (Byrne, 2010). In case the 95\% CI range did not include zero, an indirect effect was present
(Wang and Wang, 2012). Next, for all significant effects that appeared after mediation, we included age as a moderating variable and iteratively deleted non-significant effects. We also reported effect sizes for proportions of explained variances for mediating and outcome variables, 0.02 small, 0.15 medium, and 0.25 large (Cohen, 1992).

Fifth, multigroup SEM analyses (Byrne, 2010) were employed to gauge the influence of the control variables effects of job duration ( $\leq 5$ years, $>5$ years), gender (male, female), sector (healthcare, research, and education), and management position (no, yes). Finally, we tested a model in which the control variables were included as independent variables affecting job demands, job resources and employee outcomes. In the fourth and fifth stages, we employed the fit criteria described above. In all statistical analyses, alpha was set 0.05 .

\section{RESULTS}

\section{Confirmatory Factor Analysis}

Table 2 (first five rows) shows that the separate CFAs resulted in a good fit for the HRM bundles and for job resources. For job demands and employee outcomes, the models were justidentified (Hair et al., 2010, p. 699) and the fit could not be established. All standardized factor loadings were statistically significant $(p<0.001)$, ranged between 0.30 and 0.87 , and 11 (out of 24) were 0.50 or higher (see also Figure 2), there were no cross-loadings. Convergent validity estimates were acceptable. Construct reliabilities were good for all latent variables, between 0.74 and 0.93 . AVE was good for all latent variables but just below the threshold for job resources. Discriminant validity was good, that is, for all latent variables the criterion was met. In sum, the psychometric qualities of the latent variables were adequate.

The analyses confirmed maintenance and development as two distinctive factors. Of the 28 first-order items, 13 (i.e., HRM practices) loaded significantly on their intended dimension, the maintenance and development HRM bundles. Four items loaded significantly on the maintenance bundle: Flexible work, telecommuting, reduced workload, and attention for health. Nine items loaded significantly on the development HRM bundle: job development interview, career planning, continuous development, regular training, promotion, sideways movement, task enrichment, second career, and participation-indecision-making.

\section{Factor Measurement Model}

In a series of models we tested the combined factor measurement model (Table 2, model 1-y). As expected, given the complexity of the models, the fit indices were not very good. A model comparison showed that model 3 had the best fit (the combined factor model with second order factor HRM bundles containing first order factors maintenance and development, and one factor for: job demands, job resources, and employee outcomes). For the bi-factor model 6 in Table 2, SRMR could not be calculated, but it had relative good fit indices, which were comparable to those of model 3. The formative model 7 in Table 2 produced a worse fit and had much standardized factor loadings than the reflective 
TABLE 2 | Confirmatory factor analyses of latent variables $(N=1121)$.

\begin{tabular}{|c|c|c|c|c|c|c|c|c|c|c|}
\hline CFA model & CR & AVE & $x^{2}$ & $d f$ & $\times 2 / d f$ & AIC & SRMR & RMSEA & CFI & TLI \\
\hline Maintenance HRM bundle & 0.82 & 0.53 & 189 & 58 & 3.27 & 255 & 0.04 & 0.04 & 0.94 & 0.92 \\
\hline Development HRM bundle & 0.93 & 0.62 & & & & & & & & \\
\hline Job demands & 0.89 & 0.73 & a & & & & & & & \\
\hline Job resources & 0.80 & 0.47 & 10.2 & 3 & 3.38 & 34.2 & 0.02 & 0.05 & 0.99 & 0.98 \\
\hline Employee outcomes & 0.74 & 0.50 & a & & & & & & & \\
\hline Model 1 & & & 1452 & 65 & 22.3 & 1504 & 0.16 & 0.14 & 0.55 & 0.46 \\
\hline Model 2 & & & 2320 & 249 & 9.32 & 2422 & 0.12 & 0.09 & 0.60 & 0.56 \\
\hline Model 3 & & & 1967 & 246 & 8.00 & 2075 & 0.11 & 0.08 & 0.67 & 0.63 \\
\hline Model 4 & & & 3772 & 400 & 9.43 & 3903 & 0.14 & 0.09 & 0.65 & 0.62 \\
\hline Model 5 & & & 4161 & 399 & 10.4 & 4293 & 0.13 & 0.09 & 0.61 & 0.58 \\
\hline Model 6 & & & 1714 & 233 & 7.36 & 1848 & b & 0.08 & 0.71 & 0.66 \\
\hline Model 7 & & & 3721 & 263 & 14.15 & 3795 & 0.15 & 0.13 & 0.33 & 0.30 \\
\hline
\end{tabular}

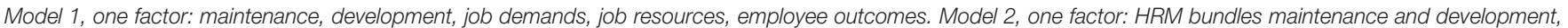

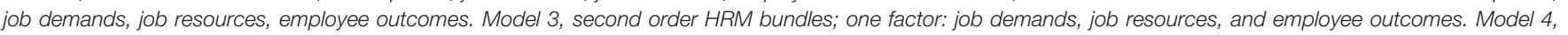

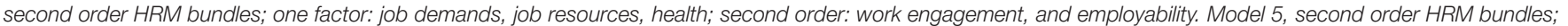

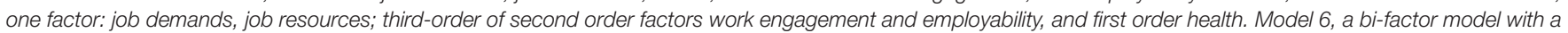

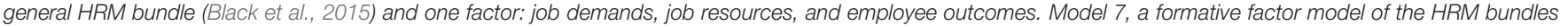

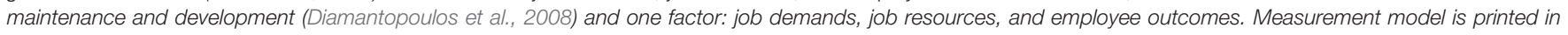

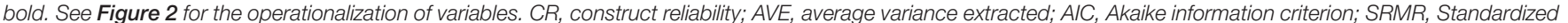

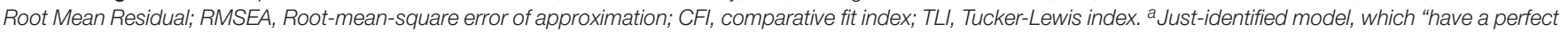
fit by definition, meaning a fit assessment is not meaningful" (Hair et al., 2010, p. 690). ${ }^{b}$ Could not be calculated.

factor solution. We therefore concluded that the distinguished HRM bundles are best described as two distinguished but related factors, maintenance and development, that represent the usage of two types of HRM practices. The other factors, job demands, job resources, and employee outcomes can be considered as one factor constructs. This factor measurement model formed the basis of the structural model used for testing hypotheses. Composite scores were computed for the number of used HRM practices per bundle, expressed as a ratio varying from 0 to 1 . For the other latent variables, weighted factor scores were used.

\section{Descriptive Results}

Table 3 presents the means, standard deviations, and correlations among all model variables. For clarity purposes, we only showed the results pertaining to the latent variables, and the moderator age. The outcomes indicated positive significant relations between the latent variables and the development HRM bundle, and job resources. However, the maintenance HRM bundle and job demands showed non-significant relationships with employee outcomes. Age was only positively correlated with job demands. The partial correlations, controlling for age, revealed that the inter-correlations of latent variables were hardly affected by age (as neither the significance nor the direction of the relationships were changed).

\section{Hypotheses Testing}

On the basis of CFAs, we specified flexible work, telecommuting, reduced workload, and attention for health as indicators of the maintenance HRM bundle. Job development interviews, career planning, continuous development, regular training, promotion, sideways movement, task enrichment, second career, and participation in decision-making were taken as indicators for the development HRM bundle. In SEM, the two HRM bundles were allowed to be correlated.

Figure 2 presents the results for the moderated mediation model. The fit of the model was adequate: $\chi^{2} / d f=70.5 / 17=4.15$, $\mathrm{AIC}=108$, SRMR $=0.04$, RMSEA $=0.05, \mathrm{CFI}=0.95$, and $\mathrm{TLI}=0.91$. Effect sizes for proportions of explained variances for job demands, job resources, and employee outcomes were up to medium/large $(0.02,0.19$, and 0.26 , respectively). The maintenance HRM bundle was not significantly related to job demands, but was significantly negatively directly related to employee outcomes $(\beta=-0.14, p<0.01)$. The maintenance HRM bundle was also indirectly positively related to employee outcomes through job resources $[\beta=0.08, p<0.01,95 \%$ CI (0.05-0.11)]. The development HRM bundle was positively related to both job demands $(\beta=0.11, p<0.001)$ and job resources $(\beta=0.35, p<0.001)$, but did not have a direct significant effect on employee outcomes. This established a complete mediation effect of the development HRM bundle on employee outcomes [indirect effect $\beta=0.17, p<0.01,95 \%$ CI (0.13-0.20)].

The moderated mediated model showed that the maintenance HRM bundle did not have a significant direct on job demands and therefore could not establish mediation which means rejection of Hypothesis 1a. Next, there was a direct negative effect as well as an indirect positive effect of the maintenance HRM bundle, via job resources, on employee outcomes. The latter implies that no support for Hypothesis $1 \mathrm{~b}$, which assumed a positive relationship, was found in our data. The effects of the development HRM bundle appeared to be completely and positively mediated by job demands and by job resources, herewith supporting Hypothesis $1 c$ and $d$.

Regarding the moderating effects of age in our assumed mediation model outlined above, we found some interesting 


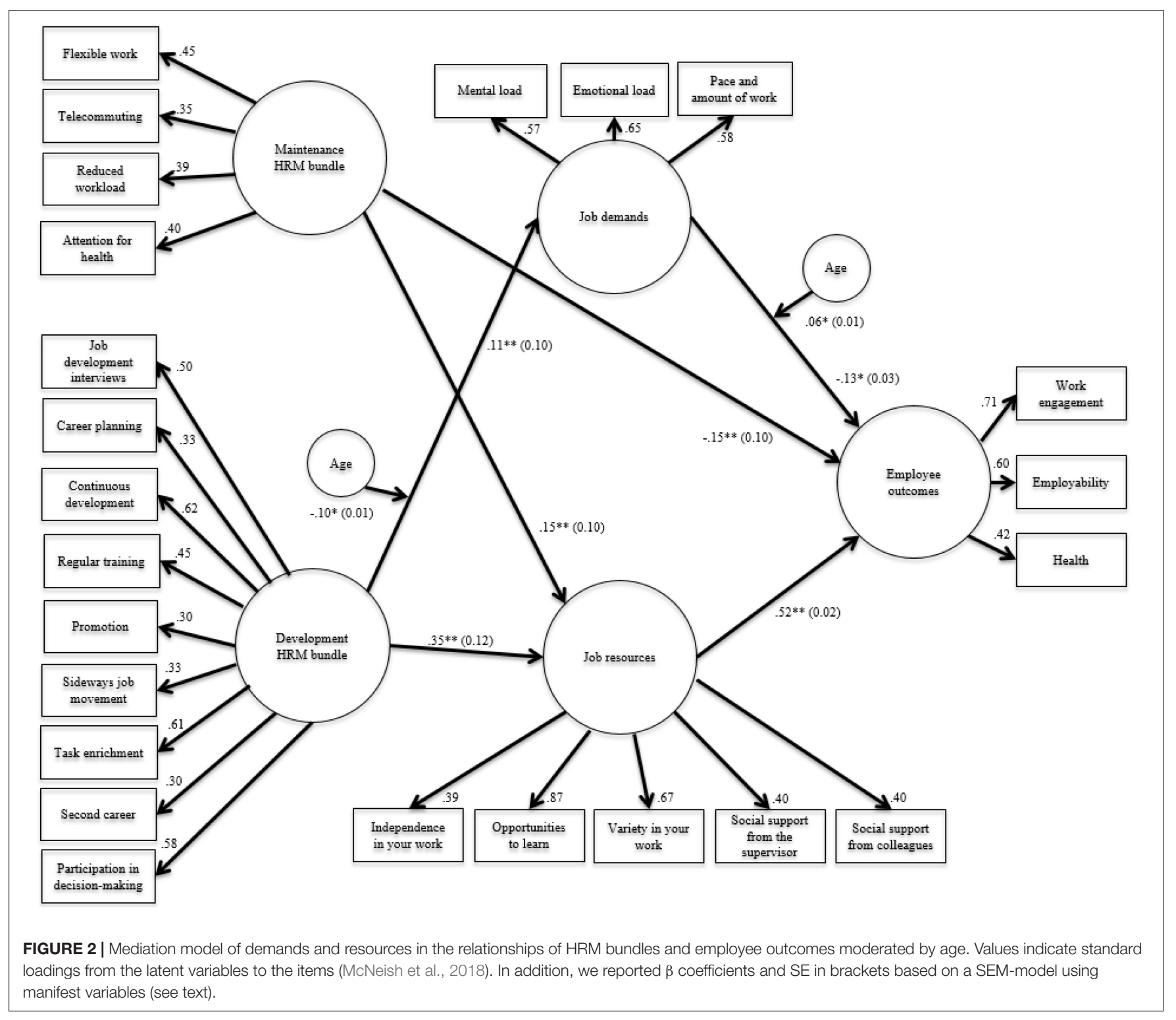

results as well. The relationship from the maintenance HRM bundle, through job resources, to employee outcomes was not moderated by age, and therefore there was no evidence for Hypothesis $2 a$. However, we did find moderating effects of age relating to job demands (see also Figure 2). More specifically, age appeared to significantly negatively moderate the relationship between the development HRM bundle and job demands $(\beta=-0.10, p<0.05)$, and positively between job demands and employee outcomes $(\beta=0.06, p<0.05)$. As age did not affect the relationship of the development HRM bundle, via job resources, on employee outcomes, Hypothesis $2 b$ was partially supported.

\section{Control Variables}

Table 4 shows the results of the multigroup analyses of the control variables job duration, gender, sector, and management position. ${ }^{2}$

\footnotetext{
${ }^{2}$ The results of the analyses of the control variables will be provided upon request.
}

By and large, the outcomes pointed to fairly robustness of the moderated mediation model (Figure 2). Regarding the association between the maintenance HRM bundle, directly and indirectly, via job resources, influencing employee outcomes, it appeared that the direct effect was especially relevant for non-managers. Pertaining to the indirect effect of the development HRM bundle, through job resources and job demands, on employee outcomes, this was particularly present among employees with a job duration $\leq 5$ years, males, employees in the healthcare sector, and non-managers. The moderation effect of age was characteristic among female employees and among those working in the research and education sector. The final model in which the control variables were included as independent variables affecting job demands, job resources and employee outcomes, showed that although there were some significant paths of the control variables (e.g., positive direct effects of management on job demands and job resources), the 
TABLE 3 | Descriptives and (partial) correlations among latent variables and age.

\begin{tabular}{|c|c|c|c|c|c|c|c|}
\hline Variable & $M$ & $S D$ & 1 & 2 & 3 & 4 & 5 \\
\hline $\begin{array}{l}\text { (1) Maintenance } \\
\text { HRM bundle }\end{array}$ & 0.26 & 0.27 & - & $0.44^{* *}$ & 0.04 & $0.30^{* *}$ & 0.01 \\
\hline $\begin{array}{l}\text { (2) Development } \\
\text { HRM bundle }\end{array}$ & 0.31 & 0.23 & $0.44^{* *}$ & - & $0.11^{* *}$ & $0.41^{* *}$ & $0.14^{*}$ \\
\hline (3) Job demands & 0.00 & 0.80 & 0.05 & $0.11^{* *}$ & - & $0.17^{* *}$ & -0.05 \\
\hline (4) Job resources & 0.00 & 0.90 & $0.28^{* *}$ & $0.41^{* *}$ & $0.17^{* *}$ & - & $0.46^{*}$ \\
\hline $\begin{array}{l}\text { (5) Employee } \\
\text { outcomes }\end{array}$ & 0.00 & 0.80 & 0.01 & $0.14^{* *}$ & -0.05 & $0.46^{* *}$ & - \\
\hline (6) Age & 46.9 & 10.2 & 0.04 & 0.01 & $0.10^{* *}$ & -0.01 & -0.00 \\
\hline
\end{tabular}

Max $N=1121$. HRM, Human Resource Management. ${ }^{*} p<0.05,{ }^{*} p<0.01$. Below diagonal Pearson's $r$ correlation coefficients are printed, above diagonal partial correlations controlling for age.

TABLE 4 | Subgroup model testing + model testing possible effects of controls.

\begin{tabular}{|c|c|c|c|c|c|c|c|c|}
\hline Groups & $x^{2}$ & $d f$ & $\chi 2 / d f$ & AIC & SRMR & RMSEA & CFI & TLI \\
\hline $\begin{array}{l}\text { Job duration } \\
\text { (years: } 1 \leq 5 ; 2>5 \text { ) }\end{array}$ & 267 & 34 & 7.87 & 343 & 0.13 & 0.11 & 0.61 & 0.36 \\
\hline Gender (male; female) & 237 & 34 & 6.97 & 313 & 0.12 & 0.07 & 0.82 & 0.70 \\
\hline $\begin{array}{l}\text { Sector (health; research } \\
\text { and education) }\end{array}$ & 237 & 34 & 6.97 & 313 & 0.10 & 0.08 & 0.79 & 0.66 \\
\hline $\begin{array}{l}\text { Management } \\
(0=\text { no; } 1=\text { yes })\end{array}$ & 167 & 34 & 4.92 & 243 & 0.05 & 0.06 & 0.87 & 0.78 \\
\hline Controls model & 228 & 35 & 6.52 & 290 & 0.08 & 0.10 & 0.69 & 0.51 \\
\hline
\end{tabular}

model fit was worse in comparison with the model in Figure 2 indicating that the control variables did not have a serious impact on the mechanisms described above.

\section{DISCUSSION}

Firstly, this study addressed the exploration of the mechanisms through which the actual use of HRM bundles, via job demands and job resources, influence employee outcomes. Secondly, due to an aging workforce (e.g., Shultz and Wang, 2011), we studied the effects of age on these aforementioned mechanisms. Thirdly, we investigated the actual use of HRM. And lastly, we went beyond studying HRM practices separately, by investigating bundles of HRM practices. Our results showed two distinct processes, in terms of mediation, one starting off from the maintenance and one from the development HRM bundles. The maintenance HRM bundle related directly negatively to employee outcomes, and indirectly through job resources in a positive way. The use of development HRM appeared to be positively related to job demands and to job resources and, subsequently, the latter to entail higher employee outcomes. Hence, our results suggest the 'driving power' of both maintenance and development HRM through job resources. However, from our analyses, we may conclude that the use of development HRM increases job demands as well, which, in turn, results in lower employee outcomes. This might refer to the so-called 'dark side' of HRM (Jensen et al., 2013), being an important outcome of our study.
Theoretically, our results were fully in line with the JD-R model assuming that job demands are associated with costs, and subsequently, relate negatively with employee outcomes. In a similar vein, we found a direct, negative relationship between maintenance HRM and employee outcomes. In particular, employees using practices from this bundle, such as flexible work conditions or attention for their health, might be encouraged to do so because of lower levels of perceived well-being, just to give an example. The build-and-broaden theory (Fredrickson et al., 2000) might help us to explain this relationship. People who are not feeling engaged are more prone to make use of HRM for the mere objective of retaining their current job. In other words, they use these practices mainly in order to survive at the labor market.

The mediating role of job resources in the relationship between maintenance and development bundles of HRM, on the one hand, and employee outcomes, on the other hand, stresses the importance of these resources. Regardless of which HRM bundle was taken as an antecedent for these resources, the latter do play an important role. This is in line with the theory of Conservation of Resources (COR; Hobfoll, 2001; Hobfoll and Shirom, 2001). At its core, COR theory is a motivational theory that focuses on protecting resources, gaining resources, and preserving resources. People employ key resources, not only to respond to stress, but also to build a reservoir of sustaining resources for times of future need. Specifically, COR theory states that people must invest resources in order to protect against resource losses, to recover from losses, and to gain resources. For example, one might invest in resources, such as increasing employees' learning opportunities, in order to counteract losses of employee engagement, due to the lack of challenges they experience in their work.

From a theoretical perspective, the development HRM bundle appears to function as a 'bipod.' In general, the process from the development HRM bundle through job demands to employee outcomes, and from the development HRM bundle through job resources to employee outcomes shows similarities with the health impairment and motivational processes in the JDR model, respectively (Demerouti et al., 2001b; Bakker et al., 2003). In a similar vein, as the JD-R model states that an investment in the growth of job resources is a more productive approach than an investment in the reduction of job demands (Bakker and Demerouti, 2008; Bakker et al., 2010; Veth et al., 2015), we may state that serious investment in both HRM bundles - accompanied with an investment in job resources is rewarding. We find evidence that particularly job resources, regardless of which HRM bundle precedes these, elicits positive employee outcomes.

Further, this study showed hardly any moderating effects of age on the relationships between HRM bundles of practices and employee outcomes. Nevertheless, interactions of age with the HRM development bundle, through job demands, and employee outcomes, showed significant differences in employees across the life-span. High job demands appear to harm all employees, regardless of their age, yet appear to be more harmful (in terms of a decrease in positive work outcomes) for aging workers. Moreover, the so-called 'dark side' effect of HRM that was found for the impact of the development HRM bundle on job demands 
was weaker for the older workers as well. Apparently, a high amount of job demands are a risk factor for all employees, and as employees age, the use of development HRM bundle may have an increasingly supportive function. Kooij and Van de Voorde (2015) argued that since older workers are better at regulating their emotions, they are better able to deal with increased workload, to mention an example, resulting in weaker negative associations between development HRM bundle and employee outcomes. Notwithstanding this moderating effect, one ought to be always cautious for a possible so-called 'dark side' effect.

As regards the third and fourth contribution of this study it is unique in its integration of the aforementioned moderating mediating relationships together with the validation of an up to now conceptually distinction of HRM bundles, and the actual use of these. So, we go beyond the perceived availability of HRM, and investigated the actual behavior, the actual use of HRM and its' relationships. Moreover, with this study we validated the conceptual distinction of Kooij et al. (2010) and validated these. So, this study points to consistent HRM practices forming a bundle targeting at higher levels of productivity and quality (MacDuffie, 1995).

To conclude, our results show a rather ambiguous effect of age on the relationship between development HRM and job demands (e.g., Kanfer and Ackerman, 2004; Zacher et al., 2018). However, in models with maintenance HRM as predictor we do not find an effect of age. This is opposed to predictions derived from the life-span theories (e.g., Baltes et al., 2006; BarnesFarrell and Matthews, 2007; Maurer, 2007), and the SOC model framework (Baltes and Baltes, 1990). These theories state that gradual changes from a focus on growth to a focus on security occur as employees age, because of age-related losses. Apparently, the use of HRM may have 'driving power' for all employees regardless of age, resulting in higher employee outcomes through job resources, although one should never ignore the possible 'dark side' effect of the development bundle of practices.

\section{Limitations}

The present study has some limitations. First, all data were collected using questionnaires, that may have resulted in biases like response set and common method variance. Second, all data were collected at one point in time, that is, the study was cross-sectional. Further research is therefore needed to address the issue of causality and reciprocal effects. As Taris and Kompier (2003) and De Lange (2005) already suggested, further research using multi-wave designs can provide more information about the stability and change of variables over time (i.e., cross-lagged designs). For instance, it might occur that, in particularly for older people, after a period of adverse health, employees may want to use more maintenance bundle HRM practices than before such of a period. Third and last, this study has been conducted in the Netherlands in three different working organizations from three occupational sectors, that are overrepresented by either males or females. The interpretation of HRM practices may be prone to cultural and sectorial biases. Nevertheless, the outcomes of our analyses provide robustness of findings across these three sectors. However, more research is needed to safely conclude on the generalizability of our results.

\section{Practical Implications}

From a practical stance, the role of HRM in retaining employees' well-being appears crucial in the realm of a continuously demanding working environment (e.g., Gould-Williams, 2007; Kuvaas, 2008; Gellatly et al., 2009; Gong et al., 2009; Taylor et al., 2012; De Lange et al., 2015). Therefore, in order to retain suitable workers for the labor market, across their working lifespan, it would be helpful for an organization to know which HRM bundles should be targeted to distinctive age groups.

This study shows that age only plays a significantly distinctive role in relation to the effect of job demands in the modeled relationships. The predominant association between the both HRM bundles and employee outcomes, through job resources, turned out to be strongly positive, regardless of age. This outcome implies that, for all age categories of workers, the use of particularly development HRM bundle is highly important and should be stimulated by (HRM) managers. However, the unexpected direct negative relationship between the maintenance HRM bundle and employee outcomes was counterbalanced in case job resources were included as a mediator in this relationship.

All in all, this study indicates that stimulating the role of job resources (the so-called 'driving power' in our model), whether they are preceded by the use of a maintenance or by a development HRM bundle, is rewarding for employees of all ages. In addition, after controlling for job duration, gender, sector, and having a management position (yes or no), we found that the process of 'driving power' applies more to employees with a job duration longer than 5 years, for men, for the education and research sector, and for managers. The 'dark side' of HRM seems to be perceived more by the counterparts: employees with job duration shorter than 5 years, women, healthcare sector, and employees without a managerial position. Our study points out that it is highly relevant to understand which and how HRM bundles influence particular employees, and employee outcomes. Hence, this study questions the contribution of age-related HRM policies. However, HRM policies focused on particular employee groups like being a non-manager, or female, turns out to be important. Managers should use the job development interviews to deepen the understanding of how the dark side can be enlightened. They should find out what exactly contributes to the dark side, and what can be done to facilitate employees. As such, our approach may establish a foundation for further theory development, and empirical research on the topic of employee well-being from the perspective of HRM.

\section{DATA AVAILABILITY STATEMENT}

The datasets generated for this study are available on request to the corresponding author.

\section{AUTHOR CONTRIBUTIONS}

KV: overall text and research. HK: methodology and statistical analyses. BV: overall text and research. BE: theoretical foundation. AL: overall text. 


\section{REFERENCES}

Albrecht, S. L., Bakker, A. B., Gruman, J. A., Macey, W. H., and Saks, A. M. (2015). Employee engagement, human resource management practices and competitive advantage: an integrated approach. J. Organ. Eff. 2, 7-35. doi: 10.1108/joepp08-2014-0042

Arbuckle, J. L. (2006). Amos 7.0 User's Guide. Chicago, IL: SPSS, Inc.

Armstrong-Stassen, M., and Schlosser, F. (2010). When hospitals provide HR practices tailored to older nurses, will older nurses stay? It may depend on their supervisor. Hum. Resour. Manag. J. 20, 375-390. doi: 10.1111/j.17488583.2010.00143.x

Bakker, A. B., and Demerouti, E. (2007). The job demands-resources model: state of the art. J. Manag. Psychol. 22, 309-328. doi: 10.1108/02683940710733115

Bakker, A. B., and Demerouti, E. (2008). Towards a model of work engagement. Career Dev. Int. 13, 209-223. doi: 10.1108/13620430810870476

Bakker, A. B., and Demerouti, E. (2014). "Job demands-resources theory," in Work and Wellbeing: Wellbeing: A Complete Reference Guide, Vol. III, eds P. Y. Chen, and L. Cooper, (Chichester: Wiley-Blackwell), 37-64.

Bakker, A. B., Demerouti, E., De Boer, E., and Schaufeli, W. B. (2003). Job demands and job resources as predictors of absence duration and frequency. J. Vocat. Behav. 62, 341-356. doi: 10.1016/s0001-8791(02)00030-1

Bakker, A. B., Van Veldhoven, M., and Xanthopoulou, D. (2010). Beyond the demand-control model: thriving on high job demands and resources. J. Pers. Psychol. 9, 3-16. doi: 10.1027/1866-5888/a000006

Bal, P. M., and De Lange, A. H. (2014). From flexibility human resource management to employee engagement and perceived job performance across the lifespan: a multi-sample study. J. Occup. Organ. Psychol. 88, 126-154. doi: 10.1111/joop.12082

Baltes, M. M. (1987). The etiology and maintenance of dependency in the elderly: three phases of operant research. Behav. Ther. 19, 301-319. doi: 10.1016/s00057894(88)80004-2

Baltes, M. M., and Carstensen, L. L. (1996). The process of successful ageing. Ageing Soc. 16, 397-422. doi: 10.1017/s0144686x00003603

Baltes, P. B., and Baltes, M. M. (1990). "Psychological perspectives on successful aging: the model of selective optimization with compensation," in Successful aging: Perspectives Form the Behavioral Sciences, eds P. B. Baltes, and M. M. Baltes, (New York, NY: Cambridge University Press), 1-34. doi: 10.1017/ cbo9780511665684.003

Baltes, P. B., Lindenberger, U., and Staudinger, U. M. (2006). "Life span theory in developmental psychology," in Handbook of Child Psychology: Theoretical Models of Human Development, 6th Edn, Vol. 1, ed. R. M. Lerner, (Hoboken, NJ: Wiley), 569-664.

Baltes, P. B., Staudinger, U. M., and Lindenberger, U. (1999). Lifespan psychology: theory and application to intellectual functioning. Annu. Rev. Psychol. 50, 471-507. doi: 10.1146/annurev.psych.50.1.471

Barnes-Farrell, J. L., and Matthews, R. A. (2007). “Age and work attitudes," in Aging and work in the 21st Century), eds K. S. Shultz, and G. A. Adams, (Mahwah, NJ: Erlbaum), 139-162.

Becker, B. E., and Gerhart, B. (1996). The impact of HRM on organizational performance: progress and prospects. Acad. Manag. J. 39, 779-801.

Black, R. A., Yang, Y., Beitra, D., and McCaffrey, S. (2015). Comparing fit and reliability estimates of a psychological instrument using second-order CFA, bifactor, and essentially tau-equivalent (coefficient alpha) models via AMOS 22. J. Psychoeduc. Assess. 33, 451-472. doi: 10.1177/0734282914553551

Bowen, D. E., and Ostroff, C. (2004). Understanding HRM-firm performance linkages: The role of the "strength" of the HRM system". Acad. Manag. Rev. 29, 203-221. doi: 10.5465/amr.2004.12736076

Byrne, B. M. (2010). Structural Equation Modeling with AMOS, Basic Concepts, Applications, and Programming. New York, NY: . Routledge, Taylor and Francis Group.

Chand, M., and Tung, R. L. (2014). The aging of the world's population and its effects on global business. Acad. Manag. Perspect. 28, 409-429. doi: 10.5465/ amp.2012.0070

Cohen, J. (1992). A power primer. Psychol. Bull. 112, 155-159.

Collins, G. A. (2003). Rethinking retirement in the context of an aging workforce. J. Career Dev. 30, 145-157. doi: 10.1177/0894845303030 00204
Conway, E., and Monks, K. (2008). HR practices and commitment to change: an employee-level analysis. Hum. Resour. Manag. J. 18, 72-89. doi: 10.1111/j.17488583.2007.00059.x

De Lange, A. H. (2005). What About Causality? Examining Longitudinal Relations Between Work Characteristics and Mental Health. Dissertation, Radboud University, Nijmegen, The Netherlands.

De Lange, A. H., Kooij, T. A. M., and Van der Heijden, B. I. J. M. (2015). “The relations between human resource management practices and sustainable work ability across the life-span," in Facing the Challenges of a Multi-Age Workforce. A Use-Inspired Approach, eds L. Finkelstein, D. Truxillo, F. Fraccaroli, and R. Kanfer, (New York, NY: Psychology Press).

De Vos, A., Van der Heijden, B. I. J. M., and Akkermans, J. (2018). Sustainable careers: Towards a conceptual model. J. Vocat. Behav. doi: 10.1016/j.jvb.2018. 06.011

Delery, J. E., and Doty, D. H. (1996). Modes of theorizing in strategic human resource management: Tests of universalistic, contingency, and configurational performance predictions. Acad. Manag. J. 39, 802-835. doi: 10.5465/256713

Demerouti, E., and Bakker, A. B. (2011). The job demands-resources model: challenges for future research. J. Ind. Psychol. 37:a974. doi: 10.4102/sajip.v37i2. 974

Demerouti, E., Bakker, A. B., De Jonge, J., Janssen, P. P. M., and Schaufeli, W. B. (2001a). Burnout and engagement at work as a function of demands and control. Scand. J. Work Environ. Health 27, 279-286. doi: 10.5271/sjweh.615

Demerouti, E., Bakker, A. B., Nachreiner, F., and Schaufeli, W. B. (2001b). The job demands-resources model of burnout. J. Appl. Psychol. 86, 499-512.

Diamantopoulos, A., Riefler, P., and Roth, K. P. (2008). Advancing formative measurement models. J. Bus. Res. 61, 1203-1218. doi: 10.3389/fpsyg.2015.01896

Ebner, N. C., Freund, A. M., and Baltes, P. B. (2006). Developmental changes in personal goal orientation from young to late adulthood: from striving for gains to maintenance and prevention of losses. Psychol. Aging 21, 664-678. doi: 10.1037/0882-7974.21.4.664

Eurostat (2013). Population Statistics at Regional Level - Statistics Explained. Brussels: Eurostat.

Field, A. (2018). Discovering Statistics Using IBM SPSS Statistics, 5th Edn. London: Sage.

Finegold, D., Mohrman, S., and Spreitzer, G. M. (2002). Age effects on the predictors of technical workers' commitment and willingness to turnover. J. Organ. Behav. 23, 655-674. doi: 10.1002/job.159

Fornell, C., and Larcker, D. (1981). Evaluating structural equation models with unobservable variables and measurement error. J. Mark. Res./ 18, 39-50. doi: $10.1177 / 002224378101800104$

Fredrickson, B. L., Mancuso, R. A., Branigan, C., and Tugade, M. M. (2000). The undoing effect of positive emotions. Motiv. Emot. 24, 237-258.

Gellatly, I. R., Hunter, K. H., Currie, L. G., and Irving, P. G. (2009). HRM practices and organizational commitment profiles. Int. J. Hum. Resour. Manag. 20, 869-884. doi: 10.1080/09585190902770794

Gong, Y., Law, K. S., Chang, S., and Xin, K. R. (2009). Human resources management and firm performance: the differential role of managerial affective and continuance commitment. J. Appl. Psychol. 94, 263-275. doi: 10.1037/ a0013116

Gould-Williams, J. (2007). HR practices, organizational climate and employee outcomes: evaluation social exchange relationships on local government. Int. J. Hum. Resour. Manag. 18, 1627-1647. doi: 10.1080/09585190701570700

Gratton, L., and Truss, C. (2003). The three-dimensional people strategy: putting human resources policies into action. Acad. Manag. Exec. 17, 74-86. doi: 10.5465/ame.2003.10954760

Guest, D. (2002). Human resource management, corporate performance and employee wellbeing: building the worker into HRM. J. Ind. Relat. 44, 335-358. doi: 10.1111/1472-9296.00053

Guest, D. E. (1997). Human resource management and performance: a review and research agenda. Int. J. Hum. Res. Manag. 8, 263-276. doi: 10.1080/ 095851997341630

Hair, J. F., Black, W. C., Babin, B. J., and Anderson, R. E. (2010). Multivariate Data Analysis. A Global Perspective, 7th Edn. Upper Saddle River, NJ: Pearson Prentice Hall

Hakanen, J. J., Schaufeli, W. B., and Ahola, K. (2008). The job demandsresources model: a three-year cross-lagged study of burnout, depression, 
commitment, and work engagement. Work Stress 22, 224-241. doi: 10.1080/ 02678370802379432

Harter, J. K., Schmidt, F. L., and Keyes, C. L. (2002). Well-being in the workplace and its relationship to business outcomes: a review of the Gallup studies. Flourishing 2, 205-224. doi: 10.1037/10594-009

Hedge, J. W., and Borman, W. C. (2012). Work and Aging, Introduction in: The Oxford Handbook of Work and Aging. New York, NY: Oxford University Press, Inc.

Hedge, J. W., Borman, W. C., and Lammlein, S. E. (2006). The Aging WorkforceRealities, Myths, and Implications for Organizations. Washington, DC: APA Press.

Hertel, G., Van der Heijden, B., De Lange, A., and Deller, J. (2013). Facilitating age diversity in organizations - part I: challenging popular misbeliefs. Special Issue J. Manag. Psychol. 28, 729-740. doi: 10.1108/JMP-07-2013-0233

Hobfoll, S. E. (2001). The influence of culture, community, and the nested-self in the stress process: advancing conservation of resources theory. Appl. Psychol. 50, 337-421. doi: 10.1111/1464-0597.00062

Hobfoll, S. E., and Shirom, A. (2001). "Conservation of resources theory: Applications to stress and management in the workplace," in Handbook of Organizational Behavior, ed. R. T. Golembiewski, (New York, NY: Marcel Dekker), 57-80.

Huselid, M. A. (1995). The impact of human resource management practices on turnover, productivity, and corporate financial performance. Acad. Manag. J. 38, 635-672. doi: 10.2307/256741

Ilmarinen, J. (2009). Work ability - A comprehensive concept for occupational health research and prevention. Scand. J. Work Environ. Health 35, 1-5. doi: 10.5271/sjweh.1304

James, L. R., Mulaik, S. A., and Brett, J. M. (2006). A tale of two methods. Organ. Res. Methods 9, 233-244.

Jensen, J. M., Patel, P. C., and Messersmith, J. G. (2013). High-performance work systems and job control consequences for anxiety, role overload, and turnover intentions. J. Manag. 39, 1699-1724. doi: 10.1177/01492063114 19663

Jöreskog, K. G., and Sörbom, D. (1993). LISREL 8: Structural Equation Modeling With the SIMPLIS Command Language. Chicago: Scientific Software International.

Kanfer, R., and Ackerman, P. L. (2004). Aging, adult development, and work motivation. Acad. Manag. Rev. 29, 440-458. doi: 10.5465/amr.2004.13670969

Keenoy, T. (1999). HRM as hologram: a polemic. J. Manag. Stud. 36, 1-23. doi: 10.1111/1467-6486.00123

Khilji, E. (2002). Modes of convergence and divergence: an integrative view of multinational practices in Pakistan. Int. J. Hum. Resour. Manag. 13, 232-253. doi: 10.1080/09585190110102350

Khilji, S. E., and Wang, X. (2006). 'Intended' and 'implemented' HRM: the missing linchpin in strategic human resource management research. Int. J. Hum. Resour. Manag. 17, 1171-1189. doi: 10.1080/09585190600756384

Kline, R. B. (2005). Principles and Practice of Structural Equation Modeling, 2nd Edn. New York, NY: The Guilford Press.

Kooij, D. T. A. M., Dikkers, J. S. E., Jansen, P. G. W., and De Lange, A. H. (2010). "A lifespan perspective on relations between HR bundles and worker outcomes. Retaining older workers: Using a case study to formulate propositions on the role of HR bundles," in Best Paper Proceedings of the Academy of Management annual meeting (Chicago).

Kooij, D. T. A. M., and Van de Voorde, K. (2015). "Strategic HRM for older workers," in Ageing Workers and the Employee-Employer Relationship, eds P. M. Bal, D. T. A. M. Kooij, and D. M. Rousseau, (New York, NY: Springer), 57-72. doi: 10.1007/978-3-319-08007-9_4

Kooij, T. A. M., De Lange, A. H., Jansen, P. G., Kanfer, R., and Dikkers, J. S. (2011). Age and work-related motives: results of a meta-analysis. J. Organ. Behav. 32, 197-225. doi: 10.1002/job.665

Kooij, T. A. M., Jansen, G. W., Dikkers, J. S. E., and De Lange, A. H. (2014). Managing aging workers: a mixed methods study on bundles of HR practices for aging workers. Int. J. Hum. Resour. Manag. 25, 2192-2212. doi: 10.1080/ 09585192.2013.872169

Korff, J., Biemann, T., Voelpel, S., Kearney, E., and Roßnagel, C. S. (2009). HR management for an aging workforce. Z. Personalpsychol. 8, 201-213. doi: 10.1026/1617-6391.8.4.201
Kuvaas, B. (2008). An exploration of how the employee-organization relationship affects the linkage between perception of developmental human resource practices and employee outcomes. J. Manag. Stud. 45, 1-25.

Lee, K., and Allen, N. J. (2002). Organizational citizenship behavior and workplace deviance: The role of affect and cognitions. J. Appl. Psychol. 87, 131-142. doi: 10.1037//0021-9010.87.1.131

Legge, K. (1995). Human Resource Management: Rhetorics and Realities (Management, work and Organisations). London: Palgrave.

Llorens, S., Schaufeli, W., Bakker, A., and Salanova, M. (2007). Does a positive gain spiral of resources, efficacy beliefs and engagement exist? Comput. Hum. Behav. 23, 825-841. doi: 10.1016/j.chb.2004.11.012

MacDuffie, J. P. (1995). Human resource bundles and manufacturing performance: organizational logic and flexible production systems in the world auto industry. Indus. Lab. Relat. Rev. 48, 197-221. doi: 10.1177/001979399504800201

Macky, K., and Boxall, P. (2007). The relationship between 'high-performance' work practices and employee attitudes: an investigation of additive and interaction effects. Int. J. Hum. Resour. Manag. 18, 537-567. doi: 10.1080/ 09585190601178745

Marsh, H. W., Hau, K. T., and Wen, Z. (2004). In search of golden rules: comment on hypothesis-testing approaches to setting cutoff values for fit indexes and dangers in overgeneralizing $\mathrm{Hu}$ and Bentler's (1999) findings. Struct. Equ. Modeling 11, 320-341. doi: 10.1207/s15328007sem1103_2

Mauno, S., Kinnunen, U., and Ruokolainen, M. (2007). Job demands and resources as antecedents of work engagement: a longitudinal study. J. Vocat. Behav. 70, 149-171. doi: 10.1016/j.jvb.2006.09.002

Maurer, T. J. (2007). "Employee development and training issues related to the aging workforce," in Aging and Work in the 21st Century, eds K. S. Shultz, and G. A. Adams, (Mahwah, NJ: Erlbaum), 163-178.

McNeish, D., An, J., and Hancock, G. R. (2018). The thorny relation between measurement quality and fit index cutoffs in latent variable models. J. Pers. Assess. 100, 43-52. doi: 10.1080/00223891.2017.1281286

Myers, N. D., Ahn, S., and Jin, Y. (2011). Sample size and power estimates for a confirmatory factor analytic model in exercise and sport: a Monte Carlo approach. Res. Q. or Exerc. Sport 82, 412-423. doi: 10.1080/02701367.2011. 10599773

Ng, T. W., and Feldman, D. C. (2008). The relationship of age to ten dimensions of job performance. J. Appl. Psycho. 93, 392-423. doi: 10.1037/0021-9010.93.2.392

Nishii, L. H., Lepak, D. P., and Schneider, B. (2008). Employee attributions of the 'why' of HR practices: their effects on employee attitudes and behaviors, and customer satisfaction. Pers. Psychol. 61, 503-545. doi: 10.1111/j.1744-6570. 2008.00121.x

Paauwe, J. (2009). HRM and performance: achievements, methodological issues and prospects. J. Manag. Stud. 46, 129-142. doi: 10.1111/j.1467-6486.2008. 00809.x

Paauwe, J., Wright, P., and Guest, D. (2013). "HRM and performance: what do we know and where should we go," in HRM and Performance: Achievements and Challenges, eds J. Paauwe, D. Guest, and P. Wright, (Chichester: Wiley), 1-13.

Pak, K., Kooij, D. T. A. M., De Lange, A. H., and Van Veldhoven, M. J. P. M. (2018). Human resource management and the ability, motivation and opportunity to continue working: a review of quantitative studies. Hum. Resour. Manag. Rev. 29, 336-352. doi: 10.1016/j.hrmr.2018.07.002

Paul, A. K., and Anantharaman, R. N. (2003). Impact of people management practices on organizational performance: analysis of a causal model. Int. J. Hum. Resour. Manag. 14, 1246-1266. doi: 10.1016/j.aap.2015.11.003

Purcell, J. (1999). Best practice and best fit: chimera or cul-de-sac? Hum. Resour. Manag. J. 9, 26-41. doi: 10.1111/j.1748-8583.1999.tb00201.x

Qualtrics Labs Inc. (2012). Qualtrics version. Provo: Qualtrics Labs Inc.

Salanova, M., Agut, S., and Peiró, J. M. (2005). Linking organizational resources and work engagement to employee performance and customer loyalty: the mediation of service climate. J. Appl. Psychol. 90, 1217-1227. doi: 10.1037/ 0021-9010.90.6.1217

Schaufeli, W. B., and Bakker, A. B. (2004). Job demands, job resources, and their relationship with burnout and engagement: a multi-sample study. J. Organ. Behav. 25, 293-315. doi: 10.1002/job.248

Schaufeli, W. B., Salanova, M., González-Romá, V., and Bakker, A. B. (2002). The measurement of engagement and burnout: a two sample confirmatory factor analytic approach. J. Happiness Stud. 3, 71-92. 
Schaufeli, W. B., Taris, T. W., and Bakker, A. B. (2006). "Dr. Jekyll and Mr. Hyde: on the differences between work engagement and workaholism," in Research Companion to Working Time and Work Addiction, ed. R. J. Burke, (Edward Elgar: Northhampton), 193-217.

Schneider, B., Ehrhart, M. G., Mayer, D. M., Saltz, J. L., and Niles-Jolly, K. (2005). Understanding organization-customer links in service settings. Acad. Manag. J. 48, 1017-1032. doi: 10.5465/amj.2005.19573107

Schreiber, J. B., Nora, A., Stage, F. K., Barlow, E. A., and King, J. (2006). Reporting structural equation modeling and confirmatory factor analysis results: a review. J. Educ. Res. 99, 323-338.

Schuler, R. S., and Jackson, S. E. (2007). Strategic Human Resource Management, 2nd Edn. Malden, MA: Blackwell.

Shultz, K. S., and Wang, M. (2011). Psychological perspectives on the changing nature of retirement. Am. Psychol. 66, 170-179. doi: 10.1037/a0022411

Snape, E., and Redman, T. (2010). HRM practices, organizational citizenship behaviour, and performance: a multi-level analysis. J. Manag. Stud. 47, 12191247.

Staudinger, U. M., Ronagel, C., and Voelpel, S. C. (2008). "Strategische Personalentwicklung und demographischer wandel: eine interdisciplinäre perspektive," in Jahrbuch Personalentwicklung 2008 - Ausbilding, Weiterbildung, eds K. Schwuchow, and J. Gutmann, (München: Management Development, Luchterhand,), 295-304.

Taris, T. W., and Kompier, M. (2003). Challenges of longitudinal designs in occupational health psychology. Scand. J. Work Environ. Health 29, 1-4. doi: $10.5271 /$ sjweh.697

Taylor, S., Osland, J., and Egri, C. P. (2012). Introduction to HRM's role in sustainability: systems, strategies, and practices. Hum. Resour. Manag. 51, 789-798. doi: 10.1002/hrm.21509

Thijssen, J. G., Van der Heijden, B. I., and Rocco, T. S. (2008). Toward the employability-link model: current employment transition to future employment perspectives. Hum. Res. Dev. Rev. 7, 165-183. doi: 10.1177/ 1534484308314955

Truss, C. (2001). Complexities and controversies in linking HRM with organizational outcomes. J. Manag. Stud. 38, 1121-1149. doi: 10.1111/14676486.00275

Van de Voorde, K., and Boxall, P. (2014). "Individual well-being and performance at work in the wider context of strategic HRM," in Well-Being and Performance at Work: The Role of Context, eds M. Van Veldhoven, and R. Peccei, (Hove: Psychology Press).

Van de Voorde, K., Paauwe, J., and Van Veldhoven, M. (2012). Employee well-being and the HRM-organizational performance relationship: a review of quantitative studies. Int. J. Manag. Rev. 14, 391-407. doi: 10.1111/j.1468-2370.2011.00322.x

Van De Voorde, K., Veld, M., and Van Veldhoven, M. (2016). Connecting empowerment-focused HRM and labour productivity to work engagement: the mediating role of job demands and resources. Hum. Resour. Manag. J. 26, 192-210. doi: 10.1111/1748-8583.12099

Van Der Heijde, C. M., and Van Der Heijden, B. I. (2006). A competence-based and multidimensional operationalization and measurement of employability. Hum. Resour. Manag. 45, 449-476. doi: 10.1002/hrm.20119

Van der Heijden, B. I. J. M. (2002). Organizational influences upon the development of professional expertise in SME's. J. Enterprising Cult. 9, 367-406. doi: $10.1142 / \mathrm{s} 0218495801000201$
Van der Heijden, B. I. J. M. (2003). Organisational influences upon the development of occupational expertise throughout the career. Int. J. Train. Dev. 7, 142-165. doi: 10.1111/1468-2419.00178

Van der Heijden, B. I. J. M., De Lange, A. H., Demerouti, E., and Van der Heijde, C. (2009). Age effects on the employability-career success relationship. J. Vocat. Behav. 74, 156-164. doi: 10.1016/j.jvb.2008.12.009

Van der Klink, J. J. L., Bultmann, U., Burdorf, A., Schaufeli, W. B., and Zijlstra, F. R. H. (2016). Sustainable employability-definition, conceptualization, and implications: A perspective based on the capability approach. Scand. J. Work Environ. Health 42, 71-79. doi: 10.5271/sjweh.3531

Van Veldhoven, M., Meijman, T. F., Broersen, J. P. J., and Fortuin, R. J. (2002). Manual Questionnaire Perception and Judgement of Work [In Dutch: Handleiding Vragenlijst Beleving en Beoordeling van de arbeid (VBBA)]. Amsterdam: SKB Vragenlijst Services.

Veth, K. N., Emans, B. J. M., Van der Heijden, B. I. J. M., Korzilius, H. K., and De Lange, A. H. (2015). Development (f)or maintenance: an empirical study on the use of and need for HR practices to retain older workers in healthcare organizations. Hum. Resou. Dev. Q. 26, 53-80. doi: 10.1002/hrdq. 21200

Wang, J., and Wang, X. (2012). Structural Equation Modeling: Applications using Mplus. Hoboken: Wiley.

Ware, J. E., and Sherbourne, C. D. (1992). The MOS 36-item short-form health survey (SF-36). Conceptual framework and item selection. Med. Care 30, 473-483. doi: 10.1097/00005650-199206000-00002

Wilson, M. G., Dejoy, D. M., Vandenberg, R. J., Richardson, H. A., and McGrath, A. L. (2004). Work characteristics and employee health and well-being: test of a model of healthy work organization. J. Occup. Organ. Psychol. 77, 565-588. doi: 10.1348/0963179042596522

World Health Organization (2016). World Health Organization. http://www. who.int/occupational_health/topics/workplace/en/index1.html (accessed April 9, 2016).

Wright, P. M., and Boswell, W. R. (2002). Desegregating HRM: a review and synthesis of micro and macro human resource management research. J. Manag. 28, 247-276. doi: 10.1016/s0149-2063(02)00128-9

Wright, P. M., Gardner, T. M., Moynihan, L. M., and Allen, M. R. (2005). The relationship between HR practices and firm performance: examining causal order. Pers. Psychol. 58, 409-446. doi: 10.1111/j.1744-6570.2005.00487.x

Zacher, H., Kooij, T. A. M., and Beier, M. E. (2018). Successful aging at work: empirical and methodological advancements. Work Aging Retire. 4, 123-128. doi: 10.1093/workar/way002

Conflict of Interest: The authors declare that the research was conducted in the absence of any commercial or financial relationships that could be construed as a potential conflict of interest.

Copyright (c) 2019 Veth, Korzilius, Van der Heijden, Emans and De Lange. This is an open-access article distributed under the terms of the Creative Commons Attribution License (CC BY). The use, distribution or reproduction in other forums is permitted, provided the original author(s) and the copyright owner(s) are credited and that the original publication in this journal is cited, in accordance with accepted academic practice. No use, distribution or reproduction is permitted which does not comply with these terms. 


\section{APPENDIX}

\section{List of HRM practices}

\author{
(1) Part-time work \\ (2) Compressed workweek \\ (3) Flexible work \\ (4) Telecommuting \\ (5) Additional leave \\ (6) Exemption from overtime working \\ (7) Early retirement
}
(8) Part-time retirement
(9) Long career break (sabbatical)
(10) Variable remuneration
(11) Flexible labor conditions
(12) Ergonomic adjustments
(13) Job development interviews
(14) Career planning

\author{
(15) Continuous development \\ (16) Regular training \\ (17) Promotion \\ (18) Demotion \\ (19) Sideways job movement \\ (20) Task enrichment \\ (21) Reduced workload
}

(22) Second career

(23) Participation in decision-making

(24) Attention for health

(25) Sport facilities

(26) Child care

(27) Paid parental leave

(28) Paid care leave 